\title{
Poor immunogenicity of a self/tumor antigen derives from peptide-MHC-I instability and is independent of tolerance
}

\author{
Zhiya Yu, ${ }^{1}$ Marc R. Theoret, ${ }^{1}$ Christopher E. Touloukian, ${ }^{1}$ Deborah R. Surman, ${ }^{1}$ Scott C. Garman, ${ }^{2}$ \\ Lionel Feigenbaum,, ${ }^{3}$ Tiffany K. Baxter, ${ }^{4}$ Brian M. Baker, ${ }^{4,5}$ and Nicholas P. Restifo ${ }^{1}$ \\ ${ }^{1}$ Surgery Branch, National Cancer Institute, NIH, Bethesda, Maryland, USA. ${ }^{2}$ Structure Biology Section, National Institute of Allergy and Infectious Diseases, \\ $\mathrm{NIH}$, Rockville, Maryland, USA. ${ }^{3}$ Science Applications International Corp., National Cancer Institute, Frederick, Maryland, USA. ${ }^{4}$ Department of Chemistry \\ and Biochemistry and ${ }^{5}$ Walther Cancer Research Center, University of Notre Dame, Notre Dame, Indiana, USA.
}

\begin{abstract}
Understanding the mechanisms underlying the poor immunogenicity of human self/tumor antigens is challenging because of experimental limitations in humans. Here, we developed a human-mouse chimeric model that allows us to investigate the roles of the frequency and self-reactivity of antigen-specific $T$ cells in determination of the immunogenicity of an epitope (amino acids 209-217) derived from a human melanoma antigen, gp100. In these transgenic mice, $\mathrm{CD8}^{+} \mathrm{T}$ cells express the variable regions of a human $\mathrm{T}$ cell receptor (hTCR) specific for an HLA-A*0201-restricted gp $1^{* 00_{209-217}}$. Immunization of hTCR-transgenic mice with gp $100_{209-217}$ peptide elicited minimal $T$ cell responses, even in mice in which the epitope was knocked out. Conversely, a modified epitope, gp100 $209-217(2 \mathrm{M})$, was significantly more immunogenic. Both biological and physical assays revealed a fast rate of dissociation of the native peptide from the HLA-A*0201 molecule and a considerably slower rate of dissociation of the modified peptide. In vivo, the time allowed for dissociation of peptide-MHC complexes on APCs prior to their exposure to $T$ cells significantly affected the induction of immune responses. These findings indicate that the poor immunogenicity of some self/tumor antigens is due to the instability of the peptide-MHC complex rather than to the continual deletion or tolerization of self-reactive $\mathrm{T}$ cells.
\end{abstract}

\section{Introduction}

Significant progress has been made in the past decade in the identification of tumor-associated antigens. More than 170 antigenic peptides derived from 60 human tumor antigens are expressed in the context of MHC molecules and are recognizable by cells in the available T cell repertoire (1). It is surprising that so many of these are nonmutated "self" antigens (2). Many candidate peptides have been used in clinical trials in efforts to develop therapeutic cancer vaccines, but most of these have failed to elicit measurable immune responses in the majority of the patients immunized, even when highly sensitive techniques for measuring these responses are used. One example of this phenomenon is illustrated in studies using a native peptide epitope derived from the human melanoma differentiation antigen, gp100. The epitope corresponding to amino acids 209-217 (ITDQVPFSV) of gp100 protein (gp100 $209-217$ ) is restricted by HLA-A*0201 and has been studied extensively in tumors from patients with metastatic malignant melanoma (3-6).

The gp100 protein is abundantly expressed in most human melanomas. High-avidity $T$ cell precursors specific to gp $100_{209-217}$ can often be identified in circulating blood and within the tumor bed $(3,4)$. Recognition of the gp $100_{209-217}$ epitope by adoptively transferred tumor-infiltrating lymphocytes has been correlated with tumor regression $(3,4)$. The nonamer gp $100_{209-217}$ peptide binds to HLA-A*0201, the most commonly expressed MHC class I molecule in patients with melanoma, with an intermediate affinity of

Nonstandard abbreviations used: human TCR (hTCR); human V $\beta 8$ (hV $\beta 8$ ); incomplete Freund's adjuvant (IFA); JR209 transgenic (JR209-Tg); T cell receptor (TCR).

Conflict of interest: The authors have declared that no conflict of interest exists.

Citation for this article: J. Clin. Invest. 114:551-559 (2004)

doi:10.1172/JCI200421695. approximately $100 \mathrm{nM}(5,7)$. Hence, this peptide was a very attractive candidate for active immunization in melanoma patients. However, attempts at immunization of HLA-A*0201-positive melanoma patients using peptide emulsified in Montanide (Seppic, Paris, France) or recombinant adenoviruses or poxviruses encoding gp100 had a minimal effect on activating the immune system to recognize the tumor antigen $(6,8,9)$. We have previously shown that native gp $100_{209-217}$ peptide is also a poor immunogen in mice transgenic for a chimeric HLA-A2/ $\mathrm{K}^{\mathrm{b}}$ molecule (10).

The reasons underlying the poor immunogenicity of many candidate antigens used in clinical trials, including the gP100 $209-217$ epitope, remain unelucidated. Nevertheless, it is clear that a modified version of this epitope (IMDQVPFSV), gp100 $209-217(2 \mathrm{M})$, in which the threonine at position 2 has been changed to a methionine, is more immunogenic in melanoma patients and in mice transgenic for the HLA- $A^{*} 0201 / \mathrm{K}^{\mathrm{b}}$ molecule $(6,8,10-12)$. The molecular bases for why modifications to a tumor-associated epitope improve immunogenicity have been the subject of some speculation. One hypothesis is that gp $100_{209-217^{-}}$specific $\mathrm{T}$ cells are present in at very low frequencies and that immunization using the altered peptide ligand $g \mathrm{p} 100_{209-217(2 \mathrm{M})}$ enables the activation of a subset of $\mathrm{T}$ cells that are cross-reactive to the native epitope, as shown in autoimmune diseases (13) as well as in tumor immunity (12). A second possibility is that the immunogenicity of a self antigen is dampened because of reduction in the number of high-affinity self-reactive $\mathrm{T}$ cells, which result from tolerating mechanisms such as clonal deletion, ignorance, anergy, or suppression in the host (14). A third theory stems from the recent understanding of the role of immunological synapses in $\mathrm{T}$ cell activation (15), in which a stable peptide-MHC complex may facilitate the formation of the synapses between $\mathrm{T}$ cells and APCs 

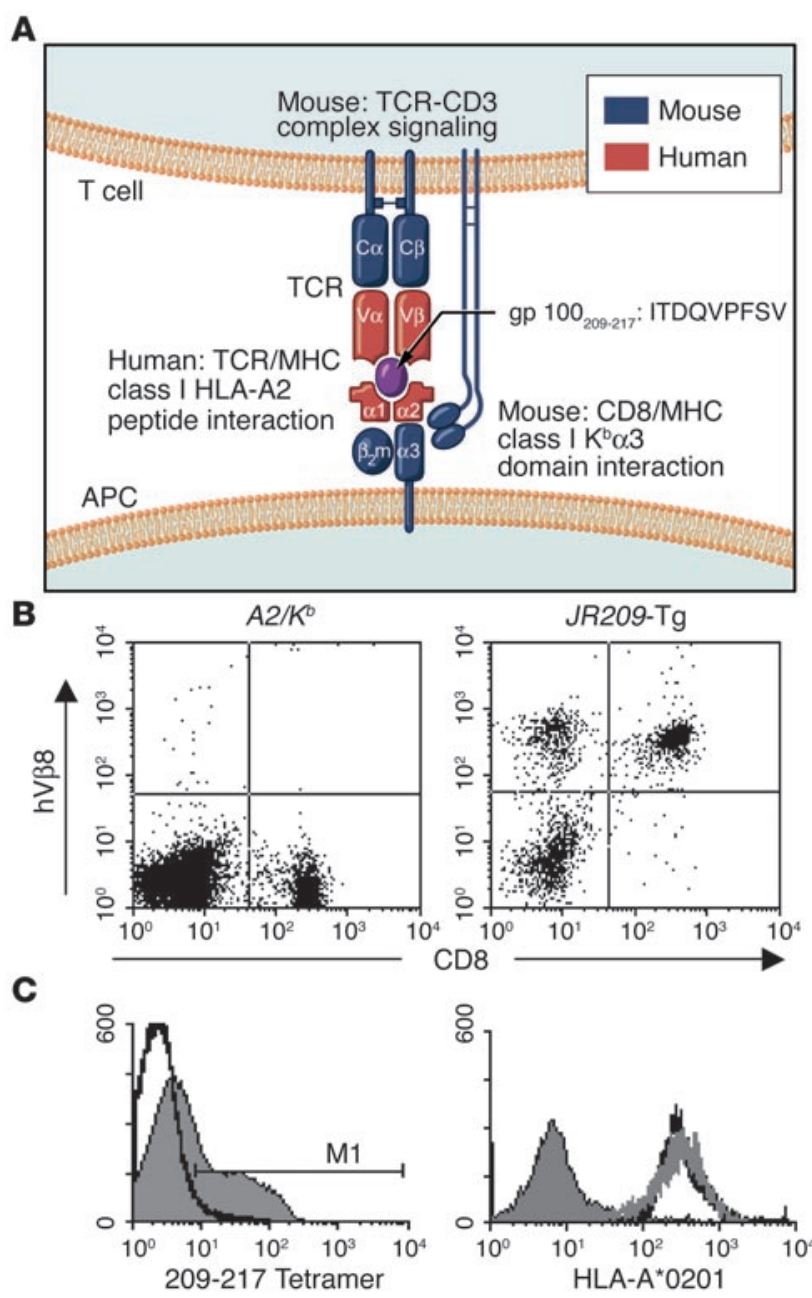

(16). The altered peptide may thus allow full $\mathrm{T}$ cell activation through sustained signaling and therefore an increased peptide immunogenicity (17), while the native peptide forms an unstable complex that could fail to fully sustain signaling. Recent studies have suggested that the immunogenicity of MHC-I-binding viral and tumor peptides were dependent on MHC-peptide complex stability (18-21). Unfortunately, without a defined T cell receptor (TCR) specificity, these studies had to assume that the frequencies and affinity of $\mathrm{T}$ cell precursors with different antigen specificities were equal in the open TCR repertoires.

Because of the clinical importance of the gp $100_{209-217}$ epitope, we sought to precisely study the molecular interaction of this relevant TCR-MHC-I-peptide complex in vivo. Numerous gp $100_{209-}$ ${ }_{217}$-specific CD8 ${ }^{+}$CTL clones have been successfully raised from melanoma patients. One of the representative clones, R6C12, was selected for this study because it was highly reactive to both native and modified gp $100_{209-217}$ peptide-pulsed T2 cells and gp $100^{+}$HLA$\mathrm{A}^{*} 0201^{+}$melanoma cells. We genetically chimerized the variable regions of human TCR (hTCR) with the constant regions of mouse TCR. In addition, the peptide-binding domains of the human HLA-A*0201 molecule were combined with mouse $\mathrm{K}^{\mathrm{b}} \alpha 3$ domains, which allow interactions with mouse CD8 coreceptors in these mice. Because the gp $100_{209-217}$ sequence is identical in mouse and man, we were able to study the in vivo activities of the transgenic T cells with a defined specificity to a true, "noninduced" self/

\section{Figure 1}

Characterization of the human-mouse TCR-HLA-A2/Kb transgenic mouse model. (A) Illustration of a hTCR-HLA-A*0201-gp $100_{209-217}$ complex in the JR209-Tg mouse model. (B) hTCR V $\beta 8$ and CD8 expression on lymphocyte-gated population from spleens of nonTCR-transgenic $A 2 / K^{b}\left(A 2 / K^{b}\right)$ and JR209-Tg littermate mice. The percentage of $\mathrm{hV} \beta 8^{+} \mathrm{CD} 8^{+}$lymphocytes was approximately 0 in $\mathrm{A2} /$ $K^{b}$ mice and 41 in JR209-Tg littermates. (C) Binding of HLA-A ${ }^{*} 201-$ gp $100_{209-217}$ tetramer to the lymphocyte-gated population from spleens of $A 2 / K^{b}$ (area under thick black line) and JR209-Tg (gray area) mice. M1 (tetramer positive gate) represented $42 \%$ of the gated population. (D) HLA-A*0201 expression on lymphocyte-gated population from splenocytes of C57BL/6 (gray area), $A 2 / K^{b}$ (area under gray line), and JR209-Tg (area under thick black line) mice.

melanoma antigen. This also provided us a unique opportunity to investigate the self-tolerance mechanisms that regulate the transgenic $\mathrm{T}$ cells in both target epitope-expressing and knockout mice. Furthermore, our transgenic model allowed us to compare the immunogenicity of the native and HLA-A*0201 anchor-modified gp100 209-217 peptides, which are both recognized by the parental human $\mathrm{T}$ cell clone. In this study, our goal was to understand the nature of the poor immunogenicity of the gp $100_{209-217}$ epitope and the precise reason why this poor immunogenicity is reversed when using the modified peptide.

\section{Results}

$T$ cells from the chimeric TCR-transgenic mouse are functional. "Humanized" TCR-transgenic mice have been previously reported only to model human $\mathrm{CD}^{+} \mathrm{T}$ cells specific to myelin basic protein in the context of HLA-DR2 (22). Our model is the first to graft human self/tumor-reactive, HLA-A2-restricted CD8 ${ }^{+} \mathrm{T}$ cells into mice (Figure 1A). To validate the bioimmunological functions of the transgenic T cells in JR209 transgenic (JR209$\mathrm{Tg}$ ) mice, we examined the number, antigen specificity, and $\mathrm{MHC}$ restriction of the transgenic T cells.

Like conventional TCR-transgenic mice, the human-mouse chimeras had an increased percentage of $\mathrm{CD} 8^{+}$lymphocytes $(40 \%)$ in the spleen compared with their TCR transgene-negative littermates (20\%) (Figure 1B), and had a similar number of total lymphocytes (not shown). More than $95 \%$ of the $\mathrm{CD}^{+} \mathrm{T}$ cells from JR209-Tg mice expressed human V $\beta 8$ (hV $\beta 8$ ) (Figure 1B). To confirm the proper TCR $V \alpha$ and $V \beta$ configurations on the transgenic T cells, we used HLA-A*0201-gp $100_{209-217}$ tetramer to label the lymphocytes. We found that approximately $40 \%$ of lymphocytes stained positive with the tetramer (Figure 1C), which was similar to the percentage of $\mathrm{CD}^{+} \mathrm{hV} \beta 8^{+}$lymphocytes (Figure $1 \mathrm{~B}$ ). The expression of HLA-A*0201 in mice with and without the transgenic TCR was similar (Figure 1D).

$\mathrm{CD}^{+} \mathrm{T}$ cells from naive JR209-Tg mice were in an inactivated state, expressing low levels of CD69 and CD44 and a high level of CD62L, but no CD25 (Figure 2A). gp100 $209-217$ peptide-pulsed APCs induced IFN- $\gamma$ production by naive JR209-Tg T cells at the concentration of $10^{-8} \mathrm{M}$ (Figure $2 \mathrm{~B}$ ). After culturing in media containing $1 \mu \mathrm{M}$ of gp $100_{209-217}$ peptide and $30 \mathrm{IU} / \mathrm{ml}$ of IL-2 for 7 days, JR209-Tg T cells were fully activated. They not only phenotypically expressed high levels of CD25, CD69, and CD44 and a low level of CD62L (Figure 2A), but also secreted more IFN- $\gamma$ upon antigen stimulation (Figure 2B). These activities were peptide-specific (Figure $2 \mathrm{C}$ ) and could be blocked by mAb's against HLA-A2 and mouse CD8 (Figure 2D). 
A

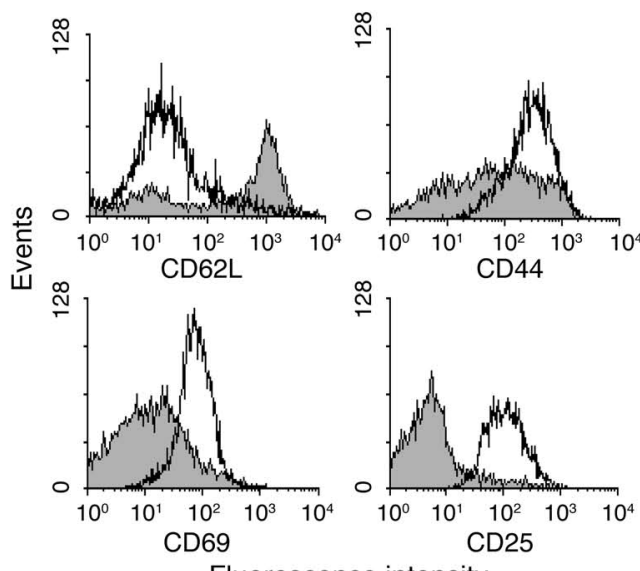

Fluorescence intensity
B

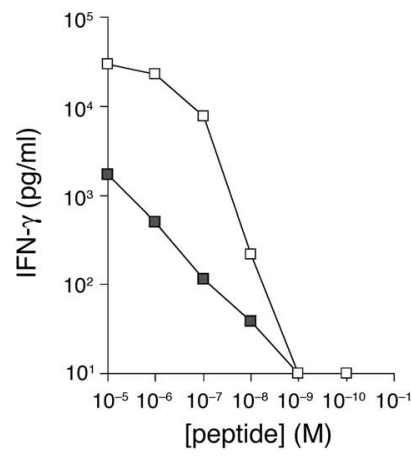

C

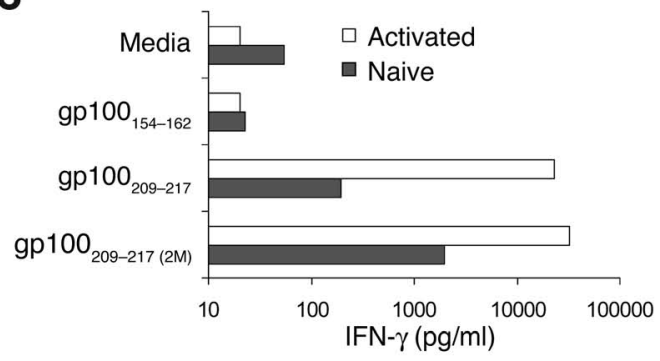

D

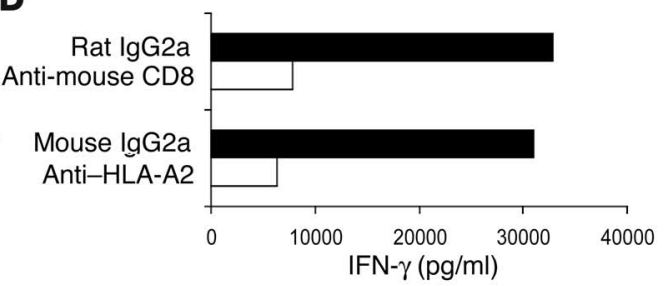

Figure 2

T cells from JR209-Tg mice are functional. (A) Expression of CD62L, CD44, CD69, and CD25 on freshly isolated (gray area) and ex vivo peptide-stimulated JR209-Tg (area under thick black line) CD8 ${ }^{+} \mathrm{T}$ cells. The florescence intensities of cells labeled with isotype Ab's were less than $10^{2}$ (not shown). (B) IFN- $\gamma$ release in 24-hour coculture of $1 \times 10^{5}$ naive (filled squares) or gp $100_{209-217}$ peptide-activated (open squares) $\mathrm{CD}^{+} J R 209-\mathrm{Tg}$ T cells and $1 \times 10^{5} \mathrm{A2} / \mathrm{K}^{b}$ splenocytes pulsed with titrated gp $100_{209-217}$ peptides. Data represented the mean of duplicate testing samples. (C) IFN- $\gamma$ release in 24 -hour coculture of $1 \times 10^{5}$ freshly isolated (gray bars) or ex vivo peptide-stimulated (white bars) CD8 ${ }^{+} J R 209-T g$ T cells and $1 \times 10^{5} \mathrm{~A} 2 / \mathrm{K}^{b}$ splenocytes pulsed with $1 \mu \mathrm{M}$ of gp100 $209-217(2 \mathrm{M})$, gp100 $209-217$, and gp 100 ${ }_{154-162}$ (irrelevant control) peptide. (D) IFN- $\gamma$ release in 24-hour coculture of $1 \mu \mathrm{M}$ gp $100_{209-217}$ peptide-pulsed $A 2 / K^{b}$ splenocytes and activated $J R 209-\mathrm{Tg} \mathrm{T}$ cells and their blockade by anti-HLA-A2 and anti-mCD8 mAb's. Data represent the mean of duplicate testing samples.

We noticed that about $20 \%$ of lymphocytes in the spleen of the $J R 209-\mathrm{Tg}$ mice were $\mathrm{CD} 4^{+} \mathrm{T}$ cells that also expressed human $V \beta 8$ transgene. These $\mathrm{CD} 4^{+} \mathrm{T}$ cells did not proliferate in response to in vitro stimulation with gp $100_{209-217}$ peptide (data not shown), and their functions were not known.

Tolerance is observed in JR209-Tg mice with the gp100 $209-217$ epitope knockout. Despite large numbers of circulating antigen-specific $\mathrm{CD}^{+} \mathrm{T}$ cells and the expression of target antigens in normal melanocytes and other pigmented cells in eyes and brain, no significant changes in the color or appearance of hair, skin, or eyes were observed in JR209-Tg mice compared with nontransgenic littermates. To test whether these self-reactive $T$ cells were tolerized, we compared the lymphocytes in JR209-Tg mice and JR209$\mathrm{Tg}$ mice in which the gp $100_{209-217}$ epitope was disrupted by insertion of the neomycin gene into exon 4 (corresponding to cDNA sequence 636-902 bp) of the gp100 gene. This resulted a truncation of gp100 protein from amino acid 212.

Although the numbers of thymocytes and splenocytes in both types of JR209-Tg mice were similar, naive splenocytes from JR209-Tg-gp100 $209-217^{K O}$ mice produced more IFN- $\gamma$ within 24 hours of peptide-APC stimulation than did those from JR209$T g-g p 100_{209-217^{W T}}$ mice expressing the epitope (Table 1 ). The differences between the naive self and non-self JR209-Tg T cells seemed to be more obvious when the antigen-specific proliferative responses were examined. In the absence of exogenous IL-2 in the culture media, more than $70 \%$ of JR209-Tg T cells from naive non-epitope-expressing mice had divided at least once within 48 hours of gp $100_{209-217}$ stimulation. In comparison, less than $20 \%$ of JR209-Tg T cells from epitope-expressing mice had divided in the same period of time (Figure 3A). The sensitivity of JR209-Tg T cells to gp $100_{209-217}$ epitope concentrations in ex vivo assays was similar regardless of the expression of the epitope
(Table 1), which indicated unchanged TCR affinity in both types of mice. When JR209-Tg T cells were cultured ex vivo with antigen and IL-2 (known to reverse anergy of self-reactive T cells; see ref. 23), the differences in IFN- $\gamma$ production and proliferation between the cells from epitope-expressing and nonexpressing mice diminished (data not shown). Our experimental results indicated that self-tolerance mechanisms partially abrogate the early $\mathrm{T}$ cell activation events.

Native gp100 $209-217$ antigen fails to immunize JR209-Tg T cells in the epitope-expressing and knockout mice. To investigate whether the poor immunogenicity of the gp $100_{209-217}$ epitope was due to the low frequency of self-reactive $T$ cells, we compared immune responses induced by peptides in JR209 TCR-transgenic and non-TCR-transgenic $A 2 / K^{b}$ mice (or $A 2 / K^{b}$ mice). In $A 2 / K^{b}$ mice, immunization with neither the native nor the modified gp100 $209-217$ peptide could elicit antigen-specific $\mathrm{CD}^{+} \mathrm{T}$ cell responses, even at a $100-$ $\mu \mathrm{g}$ dose (data not shown). However, immunization of JR209-Tg mice with as little as $10 \mu \mathrm{g}$ of the modified peptide enhanced gp100 $209-217$ peptide-specific IFN- $\gamma$ production in draining lymph nodes compared with PBS controls (Figure 3B). Clearly, in the case of the modified gp $100_{209-217}$ peptide, there was a positive correlation between the frequency of antigen-specific $T$ cells and peptide immunogenicity. When we examined this correlation in JR209-Tg mice immunized with the native peptide, we found that none of the tested doses activated JR209-Tg T cells in draining lymph nodes compared with PBS controls (Figure 3B). Our data indicated that the quantity of tumor-specific $T$ cells was not a determining factor for the failure of the native gp $100_{209-217}$ peptide to immunize.

To investigate whether self-tolerance was responsible for the inferior immunogenicity of the native gp $100_{209-217}$ epitope, we immunized JR209-Tg-gp100 $209-217^{K O}$ mice with the peptides. Seven days after immunization, none of the tested doses activated 
A
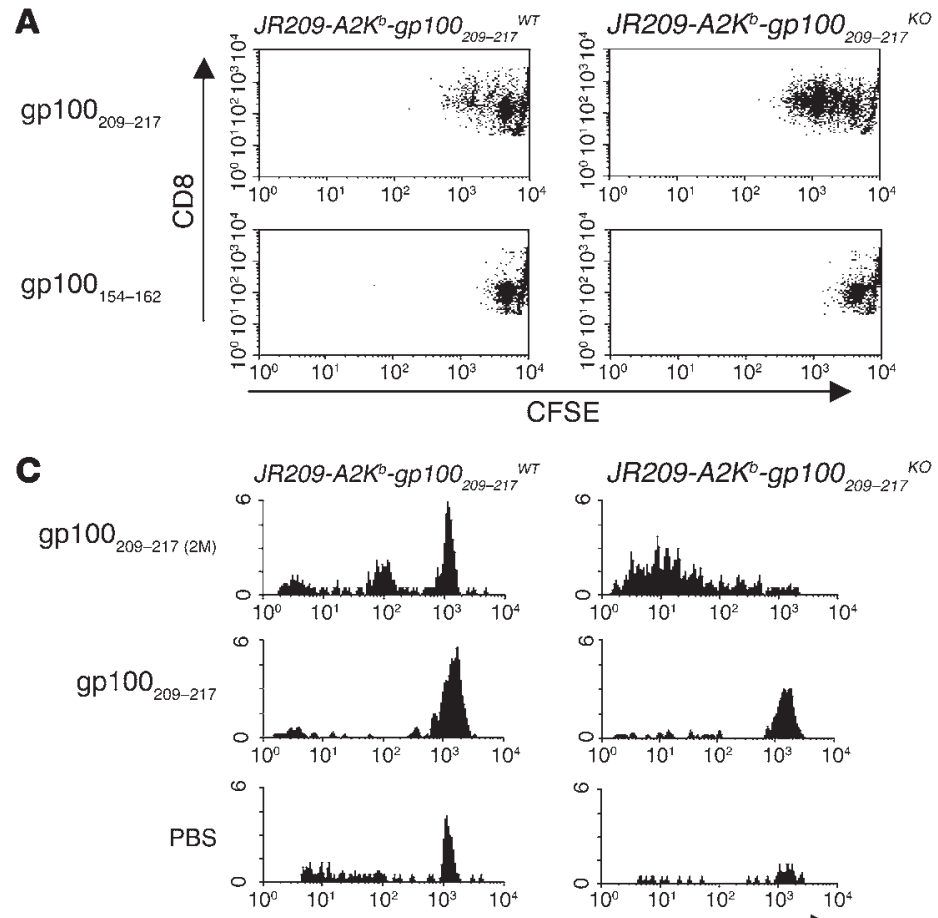

JR209-A2K $-9 p 100_{200-217}$ KO
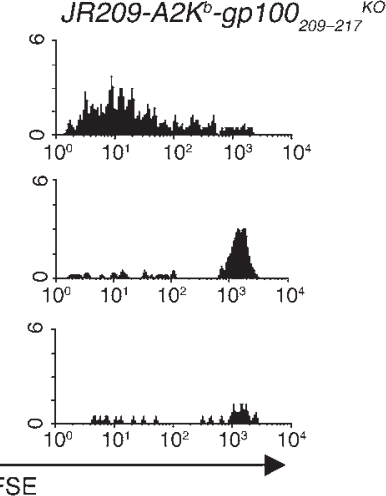

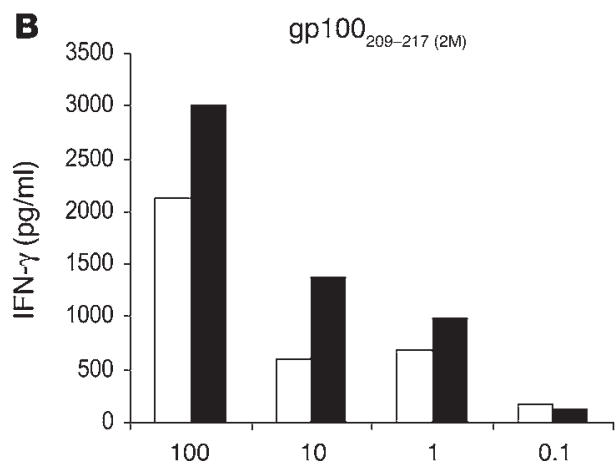

gp $100_{209-217}$

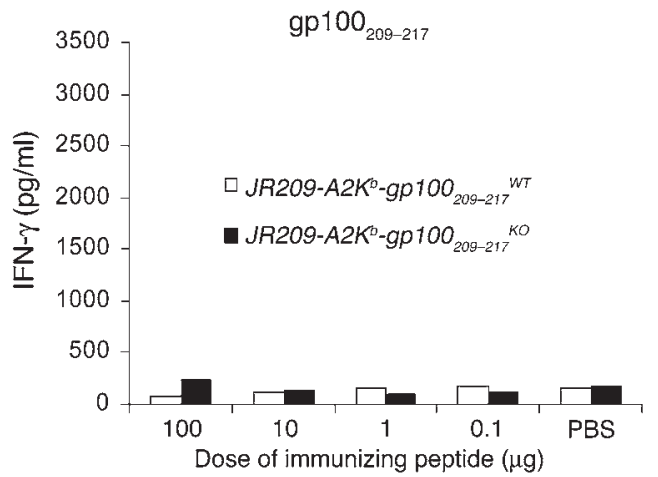

Figure 3

Native gp $100_{209-217}$ peptide fails to activate JR209-Tg T cells in both $g p 100_{209-217}{ }^{W T}$ and gp100 $209-217^{K O}$ mice. (A) Ex vivo antigen-specific proliferative responses of freshly isolated splenocytes from JR209-Tg mice with and without gp $100_{209-217}$ epitope expression. CFSE-labeled splenocytes were cultured in media containing $1 \mu \mathrm{M}$ of gp $100_{209-217}$ or gp $100_{154-162}$ peptide for 48 hours before FACS. The dot plots represent 10,000 total events in each sample. (B) gp $100_{209-217}$ peptide-specific IFN- $\gamma$ release in cells from draining lymph nodes (pooled from two mice in each group) after various doses of gp $100_{209-217(2 \mathrm{M})}$ and $\mathrm{gp} 100_{209-217}$ peptide immunization in JR209-Tg mice with (white bars) and without (black bars) the epitope expression. Draining lymph nodes were collected 7 days after immunization. One micromole of gp $100_{209-217}$ peptide was added to $1 \times 10^{5}$ cells in $200 \mu \mathrm{l}$ of culture media and incubated for 24 hours. IFN- $\gamma$ concentrations in the supernatant were determined by ELISA. (C) In vivo antigen-specific proliferative responses of adoptively transferred freshly isolated splenocytes from JR209-Tg mice with and without gp $100_{209-217}$ epitope expression. CFSE-labeled splenocytes $\left(1 \times 10^{7}\right)$ from JR209-Tg-gp $100_{209-217^{W T}}$ or JR209-Tg-gp 100 $209-217^{\mathrm{KO}}$ mice were intravenously injected into $A 2 / K^{b}$ recipient mice, followed by immunization (into the footpad) with $100 \mu \mathrm{g}$ of gp $100_{209-217(2 \mathrm{M}),} \mathrm{gp}^{2} 100_{209-217}$ peptide, or PBS (in IFA). Four days after immunization, the cells of draining lymph nodes were pooled from two mice in each group and gated on $\mathrm{hV} B 8^{+} \mathrm{CD} 8^{+} \mathrm{T}$ cells for FACS analysis.

JR209-Tg T cells in draining lymph nodes to produce antigenspecific IFN- $\gamma$ (Figure 3B). In contrast, the JR209-Tg-gp100 $209-21 T^{K O}$ mice immunized with the modified gp $100_{209-217(2 \mathrm{M})}$ peptide responded better than JR209-Tg- $g$ P100 $209-217^{W T}$ mice did (Figure 3B). When CFSE-labeled naive JR209-Tg T cells from $g p 100_{209-21 T^{W T}}$ or $g p 100_{209-217^{K O}}$ mice were adoptively transferred into HLA-A2/ $K^{b}$ recipient mice and immunized with gp $100_{209-217(2 \mathrm{M})}$ peptide, significant numbers of the transferred JR209-Tg T cells were proliferative 4 days after immunization. In addition, JR209-Tg T cells from $g p 100_{209-217^{K O}}$ mice seemed to proliferate more than those from $g p 100_{209-217^{W T}}$ mice (Figure 3C). However, 4 days after recipient mice were immunized with the native peptide, neither JR209$\mathrm{Tg} \mathrm{T}$ cells from $g p 100_{209-217^{W T}}$ mice nor those from $g p 100_{209-211^{K O}}$ mice had divided (Figure 3C). These results led us to consider factors other than self-tolerance that might contribute to the poor immunogenicity of the native epitope.

Native gp 100 209-217-MHC-I complexes are metastable. Initiation and maintenance of immunological synapses and TCR signaling following interaction with peptide-MHC complexes are essential for full activation of $\mathrm{T}$ cells $(15,17,24)$. Crystal structures of both native and modified HLA-A*0201-gp $100_{209-217}$ complexes have been recently resolved (O.Y. Borbulevych and B.M. Baker, unpublished data). Preliminary analyses indicated minimal differences in peptide binding and TCR interface structure between the native and modified gp $100_{209-217}$ peptides. This data was consistent with the observations that human $\mathrm{T}$ cell clones induced by either the native or modified peptide had no fine specificity enabling them to distinguish between the two forms of the peptide. Therefore, it is unlikely that two peptide-MHC-I complexes would result in different interactions with the TCR.

We decided to address whether the stability of the peptide-MHC-I complexes correlated to peptide immunogenicity. We determined the peptide-MHC-I dissociation rate by measuring the ability of a gp $100_{209-217-s p e c i f i c ~} \mathrm{~T}$ cell clone to recognize peptide-pulsed target cells at different time points after the peptide-MHC-I binding occurred. A human $\mathrm{T}$ cell clone specific for gp $100_{209-217}(\mathrm{CK} 3 \mathrm{H} 6)$ recognized gp $100_{209-217(2 \mathrm{M})}$ peptide-pulsed T2 cells 24 hours after binding. In contrast, recognition of gp $100_{209-217}$ peptide-pulsed T2 cells diminished 4 hours after binding. The calculated dissociation rate of the modified peptide-HLA-A2 complexes was significantly slower $(P<0.05)$ than that of native peptide-HLA-A2 (Figure 4A). Using cultured JR209-Tg T cells in which the TCR-peptide-MHC-I 
Table 1

Comparison of lymphocytes in gp $100_{209-217} \mathrm{WT}$ and gp $100_{209-217^{\mathrm{KO}}} \mathrm{JR209}-\mathrm{Tg}$ mice

\begin{tabular}{|c|c|c|c|}
\hline & $\mathrm{gp} 100_{209-217}{ }^{\mathrm{WT}}$ & gp100 $209-217^{\mathrm{KO}}$ & $P$ value \\
\hline Thymocytes & $3.4 \times 10^{7} \pm 0.6 \times 10^{7}$ & $4.3 \times 10^{7} \pm 0.8 \times 10^{7}$ & 0.3667 \\
\hline Splenocytes & $4.6 \times 10^{7} \pm 0.9 \times 10^{7}$ & $5.1 \times 10^{7} \pm 1.0 \times 10^{7}$ & 0.7020 \\
\hline $\begin{array}{l}\% \text { of } \mathrm{CD}^{+}{ }^{+} \mathrm{CD} 3^{+} \\
\mathrm{T} \text { cells in splenocytes }\end{array}$ & $38 \% \pm 4 \%$ & $37 \% \pm 5 \%$ & 0.9522 \\
\hline $\begin{array}{l}\% \text { of hV } \beta 8^{+} \mathrm{CD} 8^{+} \mathrm{CD} 3^{+} \\
\mathrm{T} \text { cells in } \mathrm{CD} 8^{+} \mathrm{CD} 3^{+} \mathrm{T} \text { cells }\end{array}$ & $93 \% \pm 2 \%$ & $92 \% \pm 2 \%$ & 0.6674 \\
\hline \multicolumn{4}{|c|}{ IFN- $\gamma$ production (pg/ml) per $10^{6}$ splenocytes } \\
\hline $1 \mu \mathrm{M} \mathrm{gp} 100_{209-217}$ & $730 \pm 75$ & $1612 \pm 202$ & $0.0149^{A}$ \\
\hline $0.1 \mu \mathrm{M} \mathrm{gp} 100_{209-217}$ & $310 \pm 31$ & $736 \pm 86$ & $0.0096^{A}$ \\
\hline $0.01 \mu \mathrm{M}$ gp $100_{209-217}$ & $91 \pm 19$ & $236 \pm 134$ & 0.3457 \\
\hline $0.001 \mu \mathrm{M} \mathrm{gp} 100_{209-217}$ & $18 \pm 8$ & $55 \pm 33$ & 0.3296 \\
\hline $1 \mu \mathrm{M}$ gp100 $154-162$ & $12 \pm 8$ & $8 \pm 4$ & 0.3486 \\
\hline
\end{tabular}

$n=5-8$ mice in each group. ${ }^{A}$ Significantly different $(P<0.05)$.

whereas the $t_{1 / 2}$ for the modified peptide was considerably greater at 27 hours. The rates from in vitro assays were slower than those reported for these biological measurements, as expected given the time required to form an immunological synapse, initiate downstream signaling events, and release IFN- $\gamma$. However, the relative differences between the rates were consistent with the biological measurements.

The affinity of the modified gp $100_{209-217}$ peptide for HLA-A2 has been reported to be approximately 9-fold stronger than that of the parental peptide $(5,7)$. As $K_{\mathrm{d}}$ is proportional to $k_{\text {off }} / k_{\text {on }}$, the $k_{\text {off }}$ measurements predict an approximate 2 -fold increase in the peptide association rate for the modified peptide. Thus the increased affinity resulting from the position 2 modification

interaction was independent of CD8 coreceptors, we found similar results as when we used human $\mathrm{T}$ cell clones (Figure $4 \mathrm{~B}$ ). Therefore, the native peptide dissociated from HLA-A2 molecules at a much faster rate than the modified peptide, which was likely to be detrimental to activation of naive $\mathrm{CD}^{+} \mathrm{T}$ cells.

The above experiments report biologically on peptide dissociation and provide apparent dissociation rates unique to the $\mathrm{T}$ cellAPC pair, yet do not directly measure the effect of modification on peptide dissociation from the HLA-A2 molecule. To investigate this, we measured peptide dissociation directly from purified, recombinant HLA-A2 using an in vitro fluorescence assay (Figure 4C). The results clearly indicated that position 2 modification resulted in slower peptide dissociation, with a dissociation rate (off-rate, or $k_{\text {off }}$ ) at $37^{\circ} \mathrm{C}$ of $0.18 \mathrm{~h}^{-1}$ for gp $100_{209-217}$ and $0.03 \mathrm{~h}^{-1}$ for gp $100_{209-217(2 \mathrm{M})}$ (i.e., the modified peptide dissociates 6 -fold slower). The difference in these rates was especially clear when we considered the $t_{1 / 2}$ of the peptide-MHC complexes, or the time required for $50 \%$ of the complex to decay. The $t_{1 / 2}$ for the parental peptide was 3.7 hours, was predominantly due to slower peptide dissociation. As peptide binding to HLA-A2 is rate-limited by a transition in the heavy chain from a "peptide-inaccessible" to a "peptide-accessible" conformation (25-27), direct calculation of $k_{\text {on }}$ values from the current data are not possible. However, preliminary measurements of association rates for the two peptides supported the conclusion that the association rate for the modified peptide was slightly faster than that of the parental peptide (T.K. Baxter and B.M. Baker, unpublished data).

Stable peptide-MHC-I complexes are required for successful induction of antitumor responses in vivo. Mouse melanoma cells expressing HLA$\mathrm{A} 2 / \mathrm{K}^{\mathrm{b}}$ molecules were not recognized by naive JR209-Tg T cells, but were recognized by activated JR209-Tg T cells (Figure $5 \mathrm{~A}$ ) due to the increased avidity for sensing the low-density antigen-MHC complexes on tumor cells (28). In JR209-Tg mice, growth of cutaneously implanted B16-A2/ $\mathrm{K}^{\mathrm{b}}$ tumor was comparable to growth in TCR transgene-negative, $A 2 / K^{b}$ mice. Only when JR209-Tg mice were immunized with both gp $100_{209-217(2 \mathrm{M})}$ peptide and IL-2 was
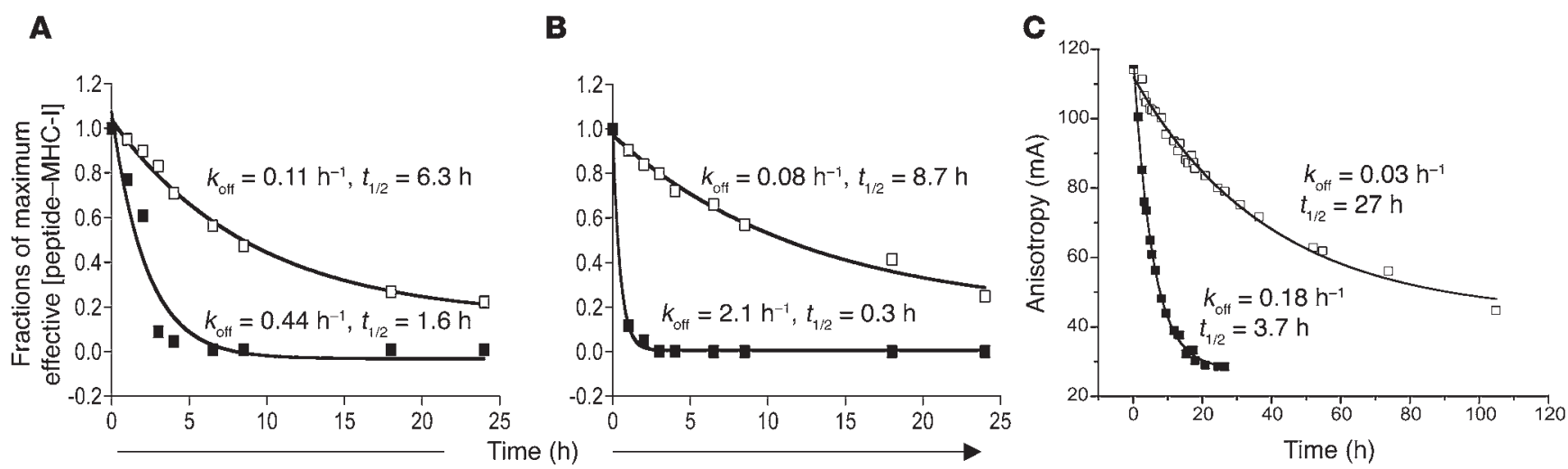

\section{Figure 4}

Native gp $100_{209-217}-\mathrm{MHC}-\mathrm{I}$ complex is metastable. (A and B) Determination of peptide dissociation rates from target cell surface. Calculated

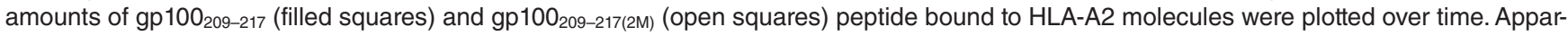
ent $k_{\text {off }}$ values were determined by fitting to a single exponential decay of all points above an undetectable concentration of peptide $\left(1 \times 10^{-10} \mathrm{M}\right.$ using human T cell clone for $\mathbf{A}$ and $1 \times 10^{-9} \mathrm{M}$ using JR209-Tg T cells for B). $t_{1 / 2}$ was determined from the relationship $t_{1 / 2}=0.693 / k_{\text {off. }}(\mathbf{C})$ Direct assay of peptide dissociation from purified peptide-MHC complexes using fluorescence anisotropy. Dissociation rates and $t_{1 / 2}$ of $g p 100_{209-217}$

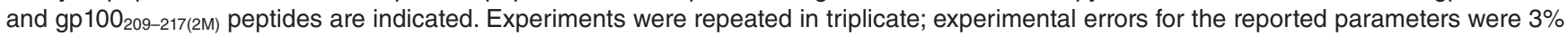
for gp $100_{209-217}$ and $7 \%$ for gp $100_{209-217(2 \mathrm{M})}$. $\mathrm{mA}$, millianisotropy. 
A
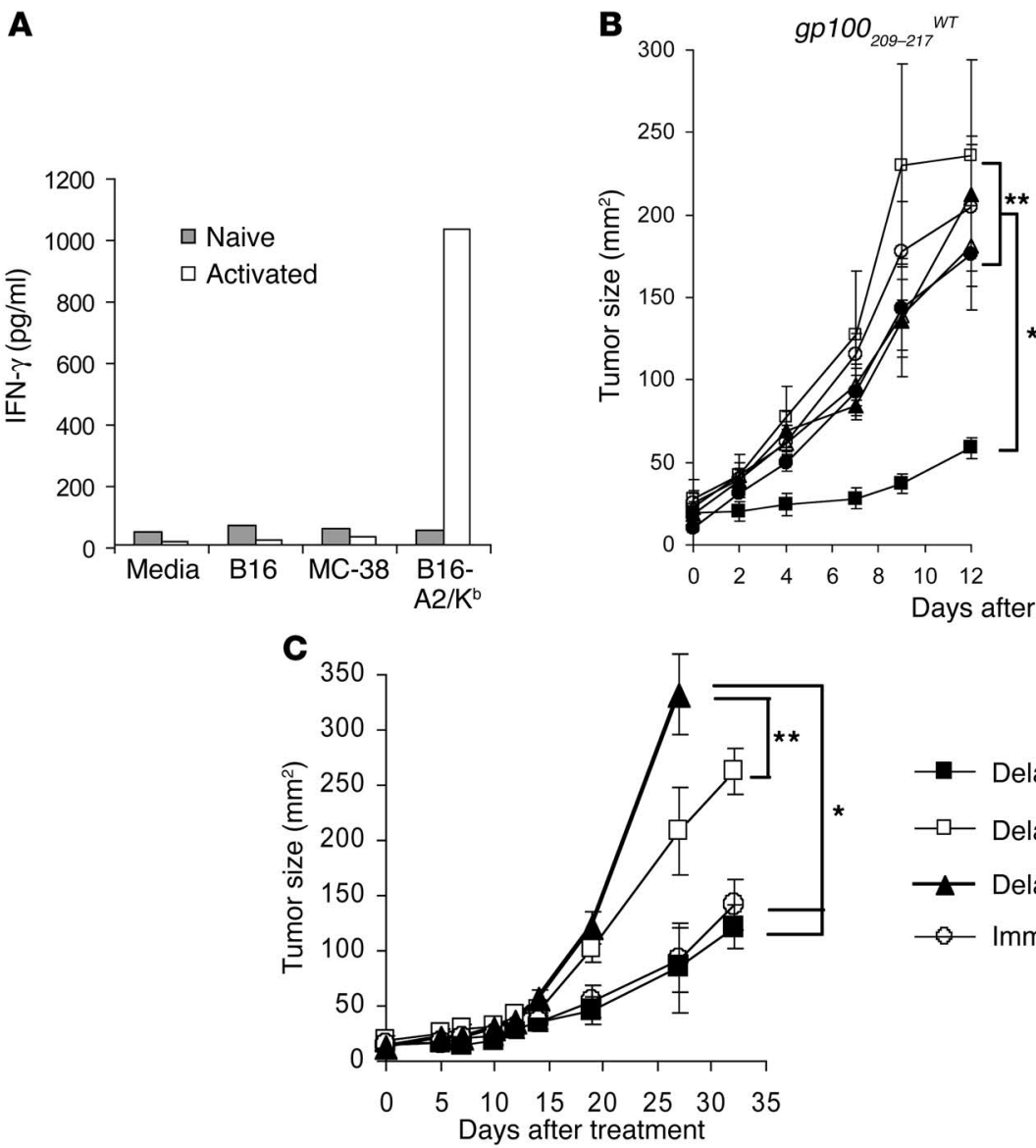

Days after treatment

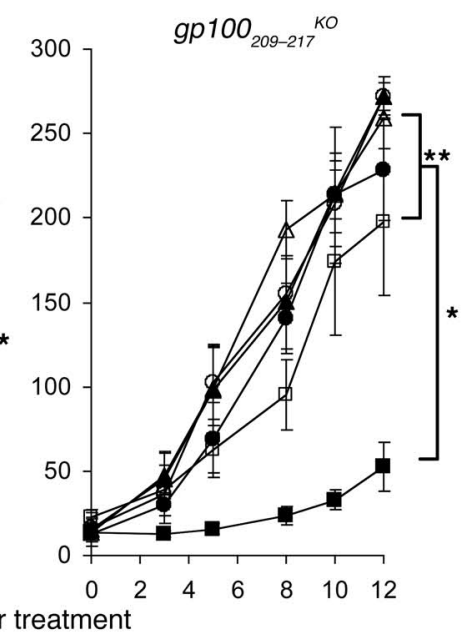

- JR209+, IFA + PBS

IFA + PBS

- JR209+ IFA + 2M

$\square$ JR209-, IFA + 2M

- JR209+, IFA + 209

- - JR209-, IFA + 209

- Delayed coculture with gp100 ${ }_{209-217(2 \mathrm{M})}$

$-\square-$ Delayed coculture with gp $100_{209-217}$

- Delayed coculture with gp100 ${ }_{154-162}$

- Immediate coculture with gp $100_{209-217}$

Figure 5

Stable peptide-MHC-I complex is required for in vivo induction of antitumor responses in JR209-Tg mice. (A) Tumor-specific IFN- $\gamma$ production by freshly isolated (gray bars) or ex vivo peptide-stimulated (white bars) CD8+ JR209-Tg T cells in 24-hour coculture with target cells from B16-A2/ $\mathrm{K}^{\mathrm{b}}$, its parental B16 melanoma, and MC-38 murine adenocarcinoma. Data represent the mean of duplicate testing samples. (B) Treatment of $\mathrm{B} 16-\mathrm{A} 2 / \mathrm{K}^{\mathrm{b}}$ tumor in $\mathrm{A} 2 / \mathrm{K}^{b}$ (open symbols) and JR209-Tg (filled symbols) mice by peptide immunization. One hundred micrograms of gp 100 $209-217$ (circles), gp100 $209-217(2 \mathrm{M})$ (squares) peptides or PBS (triangles) in IFA was subcutaneously injected into mice 13 days after tumor inoculation. Five mice were in each group. ${ }^{*}$ Significantly different $(P<0.05)$. ${ }^{* *}$ Not significantly different $(P>0.05)$. (C) Treatment of B16-A2/Kb tumor in $A 2 / K^{b}$ transgenic mice receiving adoptive transfer of ex vivo immunized $J R 209-\mathrm{Tg}$ splenocytes. Peptide-pulsed splenocytes were separated from JR209-Tg T cells for 24 hours before being cocultured overnight and then injected into tumor-bearing mice. In a control group, gp $100_{209-217}$ peptide-pulsed splenocytes were directly cocultured with JR209-Tg T cells overnight and injected into tumor-bearing mice. Seven mice were in each group.

B16-A2 $/ \mathrm{K}^{\mathrm{b}}$ tumor growth inhibited (Figure $5 \mathrm{~B}$ ). As shown in an early experiment, the native peptide failed to activate JR209-Tg T cells in vivo, and immunization of JR209-Tg mice with the native peptide and IL-2 had no impact on B16-A2/ $\mathrm{K}^{\mathrm{b}}$ tumors (Figure $5 \mathrm{~B}$ ). In JR209-Tg- $g p 100_{209-21}{ }^{K O}$ mice, B16-A2/Kb tumor also had a similar growth rate to that in TCR transgene-negative littermates. Immunizing these mice with native peptide and IL-2 did not result in the significant tumor reduction seen with the modified peptide.

Because in vivo activation of naive tumor-specific $\mathrm{CD}^{+} \mathrm{T}$ cells is known to occur in the draining lymph nodes where APCs crosspresent tumor antigens to T cells (29), we hypothesized that after peptide immunization, the stability of peptide-MHC-I complexes during the migration from immunization sites to draining lymph nodes could determine the efficiency of the induction of immune responses. To test this, we used an ex vivo model in which naive $J R 209-\mathrm{Tg} T$ cells and peptide-pulsed $A 2 / K^{b}$ splenocytes were separated for 24 hours before they were mixed in culture and trans- ferred into B16-A2/ $\mathrm{K}^{\mathrm{b}}$ tumor-bearing $H L A-A 2 / K^{b}$ mice. Tumor growth was significantly inhibited only by ex vivo immunization with the modified peptide, not the native peptide (Figure 5C). In contrast, adoptively transferred JR209-Tg T cells that were stimulated ex vivo with $H L A-A 2 / K^{b}$ splenocytes immediately after native peptide pulsing inhibited tumor growth (Figure 5C). Therefore, the level of available gp $100_{209-217}-\mathrm{MHC}$ complexes on APCs at the time they encounter $\mathrm{CD}^{+} \mathrm{T}$ cells could have a dramatic impact on an antigen's ability to sensitize T cells.

\section{Discussion}

The JR209-Tg mouse model presents a magnified picture of the interactions between a human self/tumor antigen-specific $\mathrm{CD}^{+}$ $\mathrm{T}$ cell and its cognate peptide-MHC-I ligand. This model clearly shows that a stable peptide-MHC-I complex is the first requirement for activating self-reactive $\mathrm{CD}^{+} \mathrm{T}$ cells during peptide immunization. It not only explains the poor immunogenicity of 
vaccines based on nonmodified tumor antigens, but also elucidates a plausible escape mechanism for autoreactive $\mathrm{T}$ cells with intermediate affinity to self/tumor antigens.

One mechanism by which autoreactive $\mathrm{T}$ cells escape negative selection is the lack of tissue-specific antigen expression in the thymus (30). This is unlikely in the case of JR209-Tg T cells because gp100 is highly expressed in mouse thymic epithelial and dendritic cells (31). We have shown that the number of JR209-Tg $\mathrm{T}$ cells in $g p 100_{209-217^{W T}}$ mice is comparable to the number found in $g p 100_{209-217^{K O}}$ mice. Therefore, the majority of JR209-Tg T cells escape thymic selection regardless of antigen expression. A possible explanation is that with a very fast rate of dissociation, the gP100 $209-217$ epitope-MHC-I complex is not stable enough to initiate TCR signaling in the thymus and thus fails to clonally delete the self-reactive $T$ cells.

However, in the periphery, JR209-Tg T cells have reduced responsiveness to self-antigen stimulation compared with those that mature in a self antigen-free environment. If the self-reactive $\mathrm{T}$ cells do not "see" the antigen, there is no need to downregulate their response to it. Therefore, ignorance cannot explain the reduced responsiveness of tolerized $J R 209-\mathrm{Tg} \mathrm{T}$ cells. There are fewer CD4 ${ }^{+} \mathrm{T}$ cells in JR209-Tg mice than in $A 2 / K^{b}$ mice, but it is not clear whether there are suppressive $C D 4^{+} \mathrm{T}$ cells in the JR209-Tg mice. Anergy can result in tolerization of $\mathrm{T}$ cells. Although it is not known how anergy is induced in vivo, the lack of costimulatory signals during TCR-antigen recognition is the common speculation (32). Because gp100 is abundantly expressed in melanoma and normal melanocytes, there are apparently still enough peptide-MHC complexes on the cell surface at any given time, even with a fast dissociation rate from MHC complexes. This could provide the cognate T cell signal 1 . In addition, we have evidence that IL-2, which has been shown to reverse T cell anergy (23), can restore the responsiveness of JR209$\mathrm{Tg} \mathrm{T}$ cells from $g p 100_{209-217^{W T}}$ mice to self-antigen stimulation to the same level as that of JR209-Tg T cells from $g p 100_{209-217^{K O}}$ mice. If this mouse model mimics the situation in man and many of the tumor-reactive $\mathrm{T}$ cells in the host are anergized, it is important to combine de-anergizing solutions such as common $\gamma$-chain cytokines or costimulatory factors with immunization protocols to achieve effective antitumor immune responses.

The key to understanding the poor immunogenicity of the gp $100_{209-217}$ epitope becomes apparent following analysis of the dissociation rate of peptide-MHC-I complexes. The "anchor-modified" gp100 $209-217$ peptide, in which a methionine replaces the natural threonine at position 2 of the nanomer, was predicted to fit well into the HLA-A2 binding pocket based on resolved peptide-HLAA2 crystal structures. This prediction also indicated minimal differences of the peptide surface structures facing the TCR, which agreed with the clinical findings that human $\mathrm{T}$ cell clones do not distinguish the two peptides in the context of HLA-A2 molecules $(5,6)$. Thus, it is unlikely that the gp $100_{209-217(2 \mathrm{M})}$ peptide could stimulate a subset of $\mathrm{T}$ cells that cross-react to the native antigen. We are in the process of resolving the crystal structure of the TCRpeptide-MHC-I complex to further test this prediction. The parental peptide has a 9-fold weaker binding affinity than the modified peptide $(5,7)$, due primarily to faster peptide dissociation. Thus, at any given time after initial presentation on the cell surface, a greater amount of the modified peptide remains bound to MHC-I than does its parental peptide. The correlation between this difference in dissociation rate and immunological potency was clearly dem- onstrated when peptide-pulsed APCs were separated for 24 hours before mixing; in this experiment only those cells pulsed with the modified peptide remained active. The expected 2 -fold difference in association rates was not likely to influence these results, since no exogenous peptide was present during the 24-hour incubation, ensuring that the peptide concentration outside the cell remained extremely low. Note that the 24-hour time period is not even a single half-life for the modified peptide ( $t_{1 / 2}$ of 27 hours), yet is over six half-lives for the parental peptide ( $t_{1 / 2}$ of 3.7 hours). Thus, the 100fold greater potency of the modified peptide can best be attributed to slower peptide dissociation.

It has been recently demonstrated by Spiotto et al. and Nguyen et al. that tumor antigens are cross-presented to $\mathrm{CD}^{+} \mathrm{T}$ cells in draining lymph nodes by professional APCs $(29,33)$. Using real-time two-photon microscopy, Bousso et al. elegantly illustrated the dynamics of $\mathrm{CD}^{+} \mathrm{T}$ cell priming by dendritic cells in intact lymph nodes. Contrary to conventional wisdom, it takes hours, not minutes, for APCs to activate naive $\mathrm{CD}^{+} \mathrm{T}$ cells (34). Antigen uptake by an APC either at the tumor site or at the peptide immunization site, migration to draining lymph nodes, and stable contact with an antigen-specific $\mathrm{T}$ cell could take hours and possibly days. Therefore, the stability of peptide-MHC-I complexes becomes an important determinant of the immunogenicity of a given antigen.

In our transgenic mouse model, because the variable regions of the TCR were fixed, we could not address the issue brought by cross-reactive $\mathrm{T}$ cells. However, clinically it has become evident that $\mathrm{T}$ cells reactive to self/melanoma antigens with high avidity (capable of recognizing $1 \mathrm{nM}$ or less peptide) do exist in humans $(18,35-37)$, which perhaps explains why immunotherapy is more efficient in treating patients with melanoma than those with other cancers. We have successfully isolated and cloned a $\mathrm{CD}^{+} \mathrm{T}$ cell specific for the gp100 mouse homologue Pmel-17, residues 25-33 from normal C57BL/ 6 mice that were immunized with recombinant vaccinia virus expressing human gp100. This clone was able to recognize target cells pulsed with self-peptide at a level as low as $1 \mathrm{pM}$ (38). Transgenic T cells derived from this clone, antigenic stimulation, and the administration of IL-2 have been demonstrated to be three inseparable necessities to successfully destroy cutaneously implanted solid syngeneic murine melanoma (39). Clearly, there are mechanisms regulating the function of these high-avidity autoreactive $\mathrm{T}$ cells in the host to prevent autoimmune diseases; however, in cancer immunotherapy, the goal is the opposite. In our study, we demonstrated that the strength of the stable peptide-MHC-I complexes could determine an antigen's ability to break the self-tolerance in the host. As numerous approaches are undergoing investigation in the field, we strongly recommend modifying the selected epitope to achieve the maximum stability of peptide-MHC-I complexes for effective immunization against self/tumor antigens.

\section{Methods}

Peptide synthesis. Native and modified gp100 $109-217$ peptides (ITDQVPFSV and IMDQVPFSV, respectively) were synthesized by Macromolecular Resources (Colorado State University, Fort Collins, Colorado, USA). They were more than $95 \%$ pure by HPLC analysis. All the peptides were dissolved in DMSO at $10 \mathrm{mg} / \mathrm{ml}$ as stock for ex vivo use. Fluorescently labeled peptides, modified at position 5 with a fluorescein-derivatized lysine [ITDQ(K-Flc)PFSV and IMDQ(K-Flc)PFSV], were synthesized by SynPep Corp. (Dublin, California, USA) and were HPLC-purified to greater than $95 \%$ purity. 
Production of transgenic mice expressing buman gp100 209-217-specific TCRs. R6C12, an HLA-A*0201-restricted, gP100 $209-217$-specific $\mathrm{CD}^{+} \mathrm{T}$ cell clone derived from a melanoma patient was selected for hTCR cloning. The basic procedures used to identify and clone the TCR were adopted from the methods described by Kouskoff et al. (40). Briefly, the VJ fragments of the $\alpha$ chain and the VDJ fragments of the $\beta$ chain were cloned by $5^{\prime}$ rapid amplification of cDNA ends and identified by DNA sequencing as $V \alpha 41 S 1, J \alpha 54, V \beta 8 S 1, D \beta 2$, and Jß2S1. Genomic DNA of the TCR $\alpha$ and $\beta$ chain, from the 10-12 bp upstream of the start codon and up to the 200-bp intronic sequences downstream of the junction regions, were PCR amplified and inserted into pT $\alpha$ and $\mathrm{pT} \beta$ cassette vectors, respectively (kindly provided by Diane Mathis of Harvard University School of Medicine, Boston, Massachusetts, USA). The inserted genomic DNA fragments were verified by restriction enzyme digestion. After removing the prokaryote DNA sequences, the linearized $\mathrm{pT} \alpha$ and $\mathrm{PT} \beta$ cassettes were coinjected into fertilized eggs from C57BL/ 6 mice. Founder mice carrying both the $\alpha$ and $\beta$ chains of the transgenic TCR were identified by Southern blot analysis. To positively select the hTCR in mice, the TCR-transgenic mice were bred to mice expressing HLA-A2/K $\mathrm{K}^{\mathrm{b}} \mathrm{MHC}$ molecules (41) (purchased from The Jackson Laboratory, Bar Harbor, Maine, USA). Transgenic mice expressing both TCR and HLA-A2/K $K^{b}$ transgenes were named JR209-Tg mice.

Expression of buman gp100 209-217-specific TCR in epitope-knockout mice. JR209-Tg mice were crossed with C56BL/6 mice lacking expression of the gp $100_{209-217}$ epitope (provided by Byoung Kwon, Indiana University, Indianapolis, Indiana, USA). Epitope-knockout mice were generated by insertion of a neomycin gene into exon 4 (corresponding to cDNA sequence 636-902 $\mathrm{bp}$ ) of the gp 100 gene. This genetic interruption resulted in a truncation of gp100 protein amino acid residue 212 and therefore eliminated the target epitope. Mice were housed at the NIH-10A animal facility and at Biocon Inc. (Rockville, Maryland, USA). All animal study protocols were approved by the NIH institutional review board.

Murine melanoma cell line engineered to express $H L A-A 2 / K^{b}$ molecules. B16 murine melanoma cells were stably transfected with plasmid DNA encoding HLA-A2 $/ \mathrm{K}^{\mathrm{b}}$ as described previously $(10)$. The expression of the transgene on the $\mathrm{B} 16-\mathrm{A} 2 / \mathrm{K}^{\mathrm{b}}$ tumor cells was monitored by FACS analysis of HLA-A2 on the cell surface.

Evaluation of JR209-Tg T cells. Freshly isolated splenocytes $\left(5 \times 10^{6}\right.$ cells $)$ from JR209-Tg mice were cultured at $37^{\circ} \mathrm{C}$ with $5 \% \mathrm{CO}_{2}$ in $2 \mathrm{ml}$ of RPMI culture media as described previously (10), containing $30 \mathrm{IU} / \mathrm{ml}$ of human recombinant IL-2 (Chiron Corp., Emeryville, California, USA) and $1 \mu \mathrm{M}$ of gp100 $209-217$ native or modified peptide in a 24-well plate. Once the cells grew confluent, they were subdivided in culture media containing IL-2.

To detect activation markers on JR209-Tg T cells upon antigen stimulation, $1 \times 10^{5}$ to $1 \times 10^{6}$ splenocytes or cultured $\mathrm{T}$ cells were stained with fluorescence-labeled mAb against hV $\beta 8$ (clone JR-2), CD25 (clone PC-61), CD62L (clone MEL-14), CD69 (clone H1.2F3), CD44 (clone TM-1), or their isotype controls (BD Biosciences - Pharmingen, San Diego, California, USA) and analyzed by FACS. In antigen-specific IFN- $\gamma$ release assays, $1 \times 10^{5}$ naive or peptide-stimulated JR209-Tg T cells were cocultured with $1 \times 10^{5}$ peptide-pulsed, irradiated (30 Gy) $H L A-A 2 / K^{b}$ splenocytes or tumor cells from B16-A2/ $\mathrm{K}^{\mathrm{b}}$, its parental B16 murine melanoma, and MC-38 murine colon adenocarcinoma (Southern Research Institute, Birmingham, Alabama, USA) in $200 \mu$ l of culture media/well of a 96-well U-bottom plate for 24 hours.

To test MHC restriction, $10 \mu \mathrm{g}$ mAb against HLA-A2 (clone KS-21; Surgery Branch, National Cancer Institute, Bethesda, Maryland, USA), CD8 (clone 53-6.7, BD Biosciences - Pharmingen), and their isotype controls were added to target cells 30 minutes before coculture. The coculture supernatants were collected 24 hours later and assayed for IFN- $\gamma$ by ELISA.

To measure the proliferation of JR209-Tg T cells in response to antigen stimulation, $1 \times 10^{6}$ freshly isolated splenocytes from naive JR209-Tg mice were labeled with $1 \mathrm{nM}$ of CFSE (Molecular Probes Inc., Eugene, Oregon, USA) and cultured in culture media with $1 \mu \mathrm{M}$ of peptide for 1-5 days before FACS for CFSE on $\mathrm{CD} 8^{+} h V \beta 8^{+}$populations.

To examine the antigen-specific proliferation in vivo of naive JR209-Tg T cells, $1 \times 10^{7}$ CFSE-labeled naive JR209-Tg splenocytes were injected intravenously into each recipient mouse, which was then immunized with 100 $\mu \mathrm{g}$ of peptide in incomplete Freund's adjuvant (IFA; Sigma-Aldrich, St. Louis, Missouri, USA) in the footpad. Three to five days later, the draining lymph nodes of immunized mice were harvested and FACS for CFSE on $\mathrm{CD}^{+} \mathrm{hV} \beta 8^{+}$populations was performed.

Tumor treatment. B16-A2/ $\mathrm{K}^{\mathrm{b}}$ melanoma cells $\left(2 \times 10^{5}\right.$ cells in $100 \mu \mathrm{l}$ of PBS) were injected intradermally into the flank region of mice. Seven to 14 days after tumor injection, mice were immunized (by injection into the footpads) with various doses of peptides emulsified in $100 \mu \mathrm{l}$ of IFA. In adoptive-transfer experiments, tumor-bearing recipient mice were given whole-body sublethal irradiation (5 Gy) followed by intravenous injection of $1 \times 10^{7}$ cultured JR209-Tg T cells. All mice in the tumor treatment experiments were given recombinant human IL-2 (Chiron Corp.) starting the day of treatment, at 600,000 IU/dose twice daily for 3 days. Tumor size was measured in a randomized, blinded fashion. Vitiligo was determined by shaving the coat hair on the abdominal area of the mice and examining the return of depigmented hair at the site.

Ex vivo modeling of peptide immunization. Splenocytes from $H L A-A 2 / K^{b}$ transgenic mice were pulsed with $1 \mu \mathrm{M}$ of peptide for 3 hours at $37^{\circ} \mathrm{C}$, washed three times with media, plated in 24 -well plates, and incubated at $37^{\circ} \mathrm{C}$ overnight. Equal numbers of freshly isolated JR209-Tg splenocytes were then added to the wells and cocultured in media containing $30 \mathrm{IU} / \mathrm{ml}$ of IL-2 for 24 hours before adoptive transfer. As a control, freshly JR209-Tg splenocytes were cocultured with APCs immediately after peptide pulsing.

Determination of peptide dissociation rates from APCs. T2 cells, derived from human lymphoma and lacking transporter associated with antigen processing, were pulsed with various concentrations of peptide for 3 hours at $37^{\circ} \mathrm{C}$ and washed three times. Peptide-pulsed T2 cells were then suspended in culture media and incubated at $37^{\circ} \mathrm{C}$ for various time periods (see Figure 4 for time points) before they were cocultured for 24 hours with a human HLA-A2-restricted $\mathrm{CD}^{+} \mathrm{T}$ cell clone specific for gp100 $209-217$ (CK3H6; Surgery Branch, National Cancer Institute) or JR209-Tg T cells stimulated with peptide for 7 days. The supernatants from the cocultures were assayed for IFN- $\gamma$ by ELISA. The correlation between the concentration of peptide-MHC complexes and IFN- $\gamma$ levels was calculated in the following manner. A regression analysis of peptide concentrations and IFN- $\gamma$ production was determined immediately after peptide pulsing. Using this correlation, the relative amount of peptideMHC-I complexes remaining on the cell surface at each time point after peptide pulsing was determined. Data were fit to a first-order rate equation of the form $y=A_{0}+\exp \left(-1 / k_{\text {off }} t\right)+y_{0}$, where $A_{0}$ is the initial amplitude, $k_{\text {off }}$ is the dissociation rate, $t$ is time, and $y_{0}$ is a baseline offset.

In vitro determination of peptide dissociation rates. Recombinant, soluble HLA-A 2 and $\beta_{2}$ m were refolded from bacterially expressed inclusion bodies as previously described (42) in the presence of fluorescently labeled native or position 2 -modified gp $100_{209-217}$ peptide. Refolded peptideMHC-I was purified chromatographically. Dissociation rates were measured using a fluorescence anisotropy assay as previously described (26). Briefly, about $7 \mathrm{nM}$ HLA-A2 loaded with fluorescent peptide was incubated at $37^{\circ} \mathrm{C}$ with a 1,000 -fold excess of unlabeled peptide, and the anisotropy was measured as a function of time using a Beacon 2000 fluorescence polarization instrument (Invitrogen Corp., Carlsbad, California, USA). The decay in anisotropy was fit to the first-order rate equation $y=A_{0}+\exp \left(-1 / k_{\text {off }} t\right)+y_{0}$, described above. The assay solution consisted of 
$10 \mathrm{mM}$ HEPES and $150 \mathrm{mM} \mathrm{NaCl}, \mathrm{pH}$ 7.4. A second kinetic phase, attributed in other reports to initial dissociation of $\beta_{2} \mathrm{~m}$ prior to dissociation of the peptide (26), was not observed for dissociation of the gp100-based peptides. Measurements were performed in triplicate.

Statistical analysis. Statistical differences in tumor growth for different treatment groups were analyzed by Wilcoxon rank sum test. A Student's $t$ test was used to compare the average cell numbers or IFN- $\gamma$ concentrations in different groups.

\section{Acknowledgments}

The authors wish to thank Diane Mathis and Byoung Kwon for generously providing transgenic mouse reagents for this study, and Mark Dudley for providing us the human $\mathrm{CD}^{+} \mathrm{T}$ cell clones and helpful discussion during the manuscript preparation. The study was supported in part by grant GM-067079 (to B.M. Baker) from the National Institute of General Medical Sciences, NIH.

Received for publication March 24, 2004, and accepted in revised form June 8, 2004.

Address correspondence to: Nicholas P. Restifo, Surgery Branch, National Cancer Institute, National Institutes of Health, Building 10, Room 2B46, Bethesda, Maryland 20892, USA. Phone: (301) 4964904; Fax: (301) 496-0011; E-mail: Nicholas_Restifo@nih.gov.
1. Van den Eynde, B., and van der Bruggen, P. 2003. Peptide database of T-cell defined tumor antigens. Cancer Immunity. [serial online]. http://www.cancerimmunity.org/peptidedatabase/Tcellepitopes. htm\#text.

2. Renkvist, N., Castelli, C., Robbins, P.F., and Parmiani, G. 2001. A listing of human tumor antigens recognized by T cells. Cancer Immunol. Immunother. 50:3-15.

3. Kawakami, Y., et al. 1995. Recognition of multiple epitopes in the human melanoma antigen gp100 by tumor-infiltrating T lymphocytes associated with in vivo tumor regression. J. Immunol. 154:3961-3968.

4. Kawakami, Y., et al. 1994. Identification of a human melanoma antigen recognized by tumorinfiltrating lymphocytes associated with in vivo tumor rejection. Proc. Natl. Acad. Sci. U. S. A. 91:6458-6462.

5. Parkhurst, M.R., et al. 1996. Improved induction of melanoma-reactive CTL with peptides from the melanoma antigen gp100 modified at HLA-A*0201binding residues. J. Immunol. 157:2539-2548.

6. Rosenberg, S.A., et al. 1998. Immunologic and therapeutic evaluation of a synthetic peptide vaccine for the treatment of patients with metastatic melanoma. Nat. Med. 4:321-327.

7. Engelhard, V.H., Bullock, T.N., Colella, T.A., Sheasley, S.L., and Mullins, D.W. 2002. Antigens derived from melanocyte differentiation proteins: self-tolerance, autoimmunity, and use for cancer immunotherapy. Immunol. Rev. 188:136-146.

8. Rosenberg, S.A., et al. 2003. Recombinant fowlpox viruses encoding the anchor-modified gp100 melanoma antigen can generate antitumor immune responses in patients with metastatic melanoma. Clin. Cancer Res. 9:2973-2980.

9. Rosenberg, S.A., et al. 1998. Immunizing patients with metastatic melanoma using recombinant adenoviruses encoding MART-1 or gp100 melanoma antigens. J. Natl. Cancer Inst. 90:1894-1900.

10. Irvine, K.R., et al. 1999. Recombinant virus vaccination against "self" antigens using anchor-fixed immunogens. Cancer Res. 59:2536-2540.

11. Phan, G.Q., et al. 2003. Immunization of patients with metastatic melanoma using both class I- and class II-restricted peptides from melanoma-associated antigens. J. Immunother. 26:349-356.

12. Bullock, T.N., Mullins, D.W., Colella, T.A., and Engelhard, V.H. 2001. Manipulation of avidity to improve effectiveness of adoptively transferred CD8(+) T cells for melanoma immunotherapy in human MHC class I-transgenic mice. J. Immunol. 167:5824-5831.

13. Oldstone, M.B. 1987. Molecular mimicry and autoimmune disease. Cell. 50:819-820.
14. Lee, P.P., et al. 1999. Characterization of circulating $T$ cells specific for tumor-associated antigens in melanoma patients. Nat. Med. 5:677-685.

15. Dustin, M.L. 2003. Coordination of T cell activation and migration through formation of the immunological synapse. Ann. N. Y. Acad. Sci. 987:51-59.

16. Slansky, J.E., et al. 2000. Enhanced antigen-specific antitumor immunity with altered peptide ligands that stabilize the MHC-peptide-TCR complex. Immunity. 13:529-538.

17. Huppa, J.B., Gleimer, M., Sumen, C., and Davis, M.M. 2003. Continuous T cell receptor signaling required for synapse maintenance and full effector potential. Nat. Immunol. 4:749-755.

18. Stanislawski, T., et al. 2001. Circumventing tolerance to a human MDM2-derived tumor antigen by TCR gene transfer. Nat. Immunol. 2:962-970.

19. Dyall, R, et al. 1998. Heteroclitic immunization induces tumor immunity. J. Exp. Med. 188:1553-1561.

20. Gold, J.S., et al. 2003. A single heteroclitic epitope determines cancer immunity after xenogeneic DNA immunization against a tumor differentiation antigen. J. Immunol. 170:5188-5194.

21. Chen, Z.W., et al. 2000. Simian immunodeficiency virus evades a dominant epitope-specific cytotoxic T lymphocyte response through a mutation resulting in the accelerated dissociation of viral peptide and MHC class I. J. Immunol. 164:6474-6479.

22. Madsen, L.S., et al. 1999. A humanized model for multiple sclerosis using HLA-DR2 and a human T-cell receptor. Nat. Genet. 23:343-347.

23. Schwartz, R.H. 1996. Models of T cell anergy: is there a common molecular mechanism? J. Exp. Med. 184:1-8.

24. Faroudi, M., Zaru, R., Paulet, P., Muller, S., and Valitutti, S. 2003. Cutting edge: T lymphocyte activation by repeated immunological synapse formation and intermittent signaling. J. Immunol. 171:1128-1132.

25. Gakamsky, D.M., Davis, D.M., Strominger, J.L., and Pecht, I. 2000. Assembly and dissociation of human leukocyte antigen (HLA)-A2 studied by real-time fluorescence resonance energy transfer. Biochemistry. 39:11163-11169.

26. Binz, A.K., Rodriguez, R.C., Biddison, W.E., and Baker, B.M. 2003. Thermodynamic and kinetic analysis of a peptide-class I MHC interaction highlights the noncovalent nature and conformational dynamics of the class I heterotrimer. Biochemistry. 42:4954-4961.

27. Springer, S., Doring, K., Skipper, J.C., Townsend, A.R., and Cerundolo, V. 1998. Fast association rates suggest a conformational change in the MHC class I molecule $\mathrm{H}-2 \mathrm{Db}$ upon peptide binding. Biochemistry. 37:3001-3012.
28. Fahmy, T.M., Bieler, J.G., Edidin, M., and Schneck, J.P. 2001. Increased TCR avidity after T cell activation: a mechanism for sensing low-density antigen. Immunity. 14:135-143.

29. Spiotto, M.T., et al. 2002. Increasing tumor antigen expression overcomes "ignorance" to solid tumors via crosspresentation by bone marrow-derived stromal cells. Immunity. 17:737-747.

30. Sprent, J., and Kishimoto, H. 2002. The thymus and negative selection. Immunol. Rev. 185:126-135.

31. Derbinski, J., Schulte, A., Kyewski, B., and Klein, L. 2001. Promiscuous gene expression in medullary thymic epithelial cells mirrors the peripheral self. Nat. Immunol. 2:1032-1039.

32. Schwartz, R.H. 2003. T cell anergy. Annu. Rev. Immunol. 21:305-334.

33. Nguyen, L.T., et al. 2002. Tumor growth enhances cross-presentation leading to limited T cell activation without tolerance. J. Exp. Med. 195:423-435.

34. Bousso, P., and Robey, E. 2003. Dynamics of CD8+ $\mathrm{T}$ cell priming by dendritic cells in intact lymph nodes. Nat. Immunol. 4:579-585.

35. Dudley, M.E., et al. 2002. Cancer regression and autoimmunity in patients after clonal repopulation with antitumor lymphocytes. Science. 298:850-854.

36. Zeh, H.J., III, Perry-Lalley, D., Dudley, M.E., Rosenberg, S.A., and Yang, J.C. 1999. High avidity CTLs for two self-antigens demonstrate superior in vitro and in vivo antitumor efficacy. J. Immunol. 162:989-994

37. Yee, C., Savage, P.A., Lee, P.P., Davis, M.M., and Greenberg, P.D. 1999. Isolation of high avidity melanoma-reactive CTL from heterogeneous populations using peptide-MHC tetramers. J. Immunol. 162:2227-2234.

38. Overwijk, W.W., et al. 1998. gp100/pmel 17 is a murine tumor rejection antigen: induction of "self"-reactive, tumoricidal T cells using highaffinity, altered peptide ligand. J. Exp. Med. 188:277-286.

39. Overwijk, W.W., et al. 2003. Tumor regression and autoimmunity after reversal of a functionally tolerant state of self-reactive CD8+ T cells. J. Exp. Med. 198:569-580.

40. Kouskoff, V., Signorelli, K., Benoist, C., and Mathis, D. 1995. Cassette vectors directing expression of $\mathrm{T}$ cell receptor genes in transgenic mice. J. Immunol. Methods. 180:273-280.

41. LaFace, D.M., et al. 1995. Human CD8 transgene regulation of HLA recognition by murine T cells. J. Exp. Med. 182:1315-1325.

42. Garboczi, D.N., Hung, D.T., and Wiley, D.C. 1992. HLA-A2-peptide complexes: refolding and crystallization of molecules expressed in Escherichia coli and complexed with single antigenic peptides. Proc. Natl. Acad. Sci. U. S. A. 89:3429-3433. 